\title{
Modeling emotion-creativity interaction following brief training
}

\author{
Xiaoqian Ding ${ }^{1}$, Rongxiang Tang ${ }^{2}$, ChangHao Jiang ${ }^{3}$, Yi-Yuan Tang ${ }^{4^{*}}$ \\ From The Twenty Third Annual Computational Neuroscience Meeting: CNS*2014 \\ Québec City, Canada. 26-31 July 2014
}

One form of meditation training, the integrative bodymind training (IBMT) has been shown to improve attention, reduce stress and change self-reports of mood [1]. Here, we examine whether short-term IBMT can improve performance related to creativity and determine the role that mood may play in such improvement using the crosslagged models.

Forty healthy Chinese undergraduates were randomly assigned to short-term IBMT group or a relaxation training (RT) control group. Mood and creativity performance were assessed by the Positive and Negative Affect Schedule [2] and Torrance Tests of Creative Thinking (TTCT) [3] respectively. ANOVAs revealed a group (IBMT vs. RT) $\times$ session (pre-training vs. post-training) interaction effect $[\mathrm{F}$ $(1,37)=14.853 ; p<.01]$ and a session main effect $[\mathrm{F}(1$, 37) $=36.156 ; p<.01]$ for TTCT. These results indicated that short-term (30 min per day for 7 days) IBMT improved creativity performance in the divergent thinking task than RT. The ANOVAs also revealed a group (IBMT vs. RT) $\times$ session (pre-training vs. post-training) interaction effect and a session main effect for positive affect (PA) and negative affect (NA) (all $p<.01$ ), indicating better emotional regulation than RT. In addition, the crosslagged models [4] were used to explore the causal sequence between PA score and TTCT score (Figure 1A) and between NA score and TTCT score (Figure 1B) before and after IBMT training. The synchronous correlations $(\mathrm{r}$ PA-before $\times$ TTCT-before $=.468, \mathrm{r}$ PA-after $\times$ TTCTafter $=.533$; r NA-before $\times$ TTCT-before $=-.499, \mathrm{r}$ NAafter $\times$ TTCT-after $=-.633$ ) and the autocorrelations $(\mathrm{r}$ PA-before $\times$ PA-after $=.823, \mathrm{r}$ TTCT-before $\times$ TTCTafter $=.591 ; \mathrm{r}$ NA-before $\times$ NA-after $=.705, \mathrm{r}$ TTCT before $\times$ TTCT-after $=.591$ ) were high in magnitude and statistically significant in the non-cross direction, which

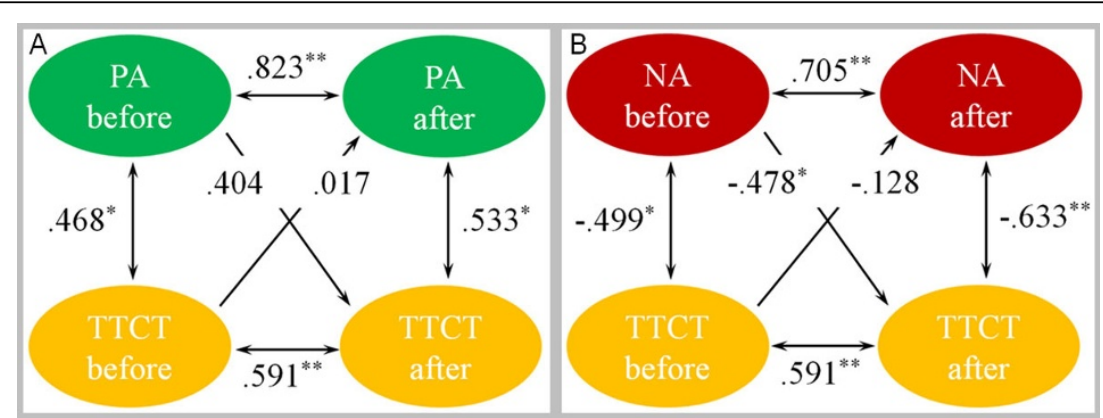

Figure 1 The causal sequence between PA score and TTCT score (A) and between NA score and TTCT score (B) before and after IBMT training. Ellipses indicate measured variables; Arrows depict hypothesized directional or "causal" links/associations; Numbers above or near measured variables represent the correlations or regressions. Spearman's correlation coefficient and the standardized regression coefficient are used and estimates are statistically significant at ${ }^{*} \mathrm{p}<.05$ and ${ }^{* *} \mathrm{p}<.01$.

\footnotetext{
* Correspondence: yiyuan.tang@ttu.edu

${ }^{4}$ Department of Psychology, Texas Tech University, Lubbock, TX79409, USA

Full list of author information is available at the end of the article
} 
provides preliminary support for cross-lagged panel correlation.

As predicted, PA had a positive cross-lagged impact on TTCT, which indicated a causal influence from positive mood changes to the creativity changes in IBMT group but not in RT group. In addition, NA had a negative cross-lagged impact on TTCT, which indicated a causal influence from negative mood changes to the creativity changes in the IBMT group but not in RT group.

\section{Conclusion}

Consistent with our previous research, the IBMT group significantly outperformed the RT group in TTCT scores and emotion after training. The cross-lagged analyses indicated that both positive and negative mood changes may contribute to the creativity changes following IBMT. Our results suggested that emotion-related creativity-promoting mechanism may be attributed to short-term meditation. Modeling emotion-creativity interaction using crosslagged analysis may open up an important avenue for studying meditation-emotion-creativity relationships.

\section{Acknowledgements}

This work was supported by the Office of Naval Research, SQKM201210029003 and PXM2013_014206_000058.

\section{Authors' details}

'Department of Physics, Dalian University of Technology, Dalian 116024, China. ${ }^{2}$ Department of Psychology, University of Texas at Austin, Austin, TX78705, USA. ${ }^{3}$ Capital University of Physical Education and Sports, Beijing 100191, China. ${ }^{4}$ Department of Psychology, Texas Tech University, Lubbock, TX79409, USA.

Published: 21 July 2014

\section{References}

1. Tang $Y Y, M a ~ Y$, Wang J, Fan Y, Feng S, Lu Q, Yu Q, Sui D, Rothbart MK, Fan M, Posner Ml: Short-term meditation training improves attention and self-regulation. Proc Natl Acad Sci U S A 2007, 104:17152.

2. Watson D, Clark LA, Tellegen A: Development and validation of brief measures of positive and negative affect: the PANAS scales. J Pers Soc Psychol 1988, 54:1063-1070.

3. Torrance EP: Predictive validity of the Torrance Tests of Creative Thinking. J Creative Behav 1972.

4. Marmor GS, Montemayor R: The cross-lagged panel design: A review. Percept Mot Skills 1977, 45:883-893.

doi:10.1186/1471-2202-15-S1-P32

Cite this article as: Ding et al:: Modeling emotion-creativity interaction following brief training. BMC Neuroscience 2014 15(Suppl 1):P32.

\section{Submit your next manuscript to BioMed Central} and take full advantage of:

- Convenient online submission

- Thorough peer review

- No space constraints or color figure charges

- Immediate publication on acceptance

- Inclusion in PubMed, CAS, Scopus and Google Scholar

- Research which is freely available for redistribution

Submit your manuscript at www.biomedcentral.com/submit
C Biomed Central 